\title{
A 2-year intercomparison of continuous-wave focusing wind lidar and tall mast wind measurements at Cabauw
}

\author{
Steven Knoop, Fred C. Bosveld, Marijn J. de Haij, and Arnoud Apituley \\ Royal Netherlands Meteorological Institute (KNMI), Utrechtseweg 297, 3731 GA, De Bilt, the Netherlands
}

Correspondence: Steven Knoop (steven.knoop@knmi.nl)

Received: 30 July 2020 - Discussion started: 8 September 2020

Revised: 18 January 2021 - Accepted: 23 January 2021 - Published: 22 March 2021

\begin{abstract}
A 2-year measurement campaign of the ZephIR 300 vertical profiling continuous-wave (CW) focusing wind lidar has been carried out by the Royal Netherlands Meteorological Institute (KNMI) at the Cabauw site. We focus on the (height-dependent) data availability of the wind lidar under various meteorological conditions and the data quality through a comparison with in situ wind measurements at several levels in the $213 \mathrm{~m}$ tall meteorological mast. We find an overall availability of quality-controlled wind lidar data of $97 \%$ to $98 \%$, where the missing part is mainly due to precipitation events exceeding $1 \mathrm{mmh}^{-1}$ or fog or low clouds below $100 \mathrm{~m}$. The mean bias in the horizontal wind speed is within $0.1 \mathrm{~m} \mathrm{~s}^{-1}$ with a high correlation between the mast and wind lidar measurements, although under some specific conditions (very high wind speed, fog or low clouds) larger deviations are observed. The mean bias in the wind direction is within $2^{\circ}$, which is of the same order as the combined uncertainty in the alignment of the wind lidars and the mast wind vanes. The well-known $180^{\circ}$ error in the wind direction output for this type of instrument occurs about $9 \%$ of the time. A correction scheme based on data of an auxiliary wind vane at a height of $10 \mathrm{~m}$ is applied, leading to a reduction of the $180^{\circ}$ error below $2 \%$. This scheme can be applied in real-time applications in the situation that a nearby freely exposed mast with wind direction measurements at a single height is available.
\end{abstract}

\section{Introduction}

Atmospheric motion and turbulence are essential parameters for weather and topics related to air quality. Therefore, wind profile measurements play an important role in atmo- spheric research and meteorology. One source of groundbased wind profile data is Doppler wind lidars, which are active, laser-based remote sensing instruments that measure wind speed and wind direction up to a few hundred metres or even a few kilometres. Like traditional radar wind profilers, Doppler wind lidars typically cover the atmospheric boundary layer very well and thereby complement other sources of wind information, such as in situ measurements at surface stations, weather radars, aircraft observations and satellite instruments.

Doppler wind lidars measure the Doppler shift of the backscattered laser light by molecules or aerosols in the moving air, by means of either direct detection or coherent detection. This Doppler shift $(\delta f)$ provides the wind velocity along the line of sight $\left(V_{\mathrm{LOS}}\right)$ via $\delta f=-2 V_{\mathrm{LOS}} / \lambda$, where $\lambda$ is the laser wavelength. Direct detection wind lidars measure the frequency spectrum of the return signal. As an example, the ADM-Aeolus space-based wind lidar, launched in 2018, is a direct detection system at a laser wavelength of $355 \mathrm{~nm}$ (Stoffelen et al., 2005). In coherent detection, the return signal is optically mixed with the local oscillator laser and the resulting beat signal provides the Doppler shift. In heterodyne coherent detection, the local oscillator is frequency shifted from the transmitted light and the beat frequency has a fixed offset. This frequency shift is absent in homodyne coherent detection and the beat frequency is the absolute value of the Doppler shift. An extensive and comprehensive description of the history and fundamentals of wind lidars can be found in Henderson et al. (2005).

Commercial coherent detection wind lidars based on the telecom wavelength of $1.5 \mu \mathrm{m}$ became available early 2000s. These systems rely solely on the aerosol signal and their range is typically limited to the atmospheric boundary layer. 
They are nowadays extensively used within the wind energy industry, for instance, for wind resource assessment and wind turbine power curve validation (Mikkelsen, 2015). For national meteorological services, like the Royal Netherlands Meteorological Institute (KNMI), data sets measured by these instruments can be valuable for model validation, while real-time access opens the possibility of data assimilation in operational numerical weather prediction (NWP) models and nowcasting purposes. For these applications, it is of utmost importance to know the meteorological conditions in which the instruments are able to provide reliable data or not.

Here, we present results of a 2-year measurement campaign of the ZephIR 300 short-range vertical profiling wind lidar at Cabauw. We focus on the (height-dependent) data availability of the wind lidar under various meteorological conditions and the data quality through a comparison with in situ wind measurements at several levels in the $213 \mathrm{~m}$ tall meteorological mast. This wind lidar instrument and its predecessors have been extensively tested (see, e.g. Smith et al., 2006; Kindler et al., 2007; Peña et al., 2009; Wouters and Wagenaar, 2016). Our campaign is unique in terms of (1) duration (more than 2 years), (2) ability to cover the full height range of the wind lidar due to the $213 \mathrm{~m}$ tall mast and (3) ability to relate the performance of the instrument to the meteorological conditions due to the co-location of many meteorological instruments on site. The location of the measurement campaign is shown in Fig. 1a, a photo of the wind lidar with the tall mast in Fig. $1 \mathrm{~b}$ and an overview of the Cabauw site in Fig. 1c.

This paper is organized as follows. We introduce the wind lidar instrument in Sect. 2, the Cabauw site in Sect. 3 and the measurement campaign in Sect. 4. Results of the intercomparison study are given in Sect. 5, focused on the $10 \mathrm{~min}$ averaged horizontal wind speed and wind direction data. Finally, we conclude and give an outlook in Sect. 6 .

\section{Wind lidar instrument}

The vertical profiling wind lidar of the measurement campaign is the ZephIR 300 (ZX Lidars, UK, formerly ZephIR Lidar). The ZephIR 300 is a homodyne coherent detection continuous-wave $(\mathrm{CW})$ focusing wind lidar. The laser beam is transmitted through a constantly rotating prism (wedge) to perform a so-called velocity azimuth display (VAD) scan. The scanning cone angle is $30^{\circ}$ (with respect to zenith). For each height, one complete rotation takes $1 \mathrm{~s}$, in which 50 measurements of $20 \mathrm{~ms}$ are taken, from which the 3$\mathrm{D}$ wind vector is reconstructed (i.e. horizontal and vertical wind speed, and wind direction). The manufacturer specifies the wind speed and wind direction accuracies as better than $0.1 \mathrm{~m} \mathrm{~s}^{-1}$ and $0.5^{\circ}$, respectively, and a wind speed range from $<1$ to $80 \mathrm{~m} \mathrm{~s}^{-1}$. The height range is $10-200 \mathrm{~m}$ above the instrument, although up to $300 \mathrm{~m}$ can be selected in the soft-
Table 1. Overview of the deployed ZephIR 300 wind lidar instrument.

\begin{tabular}{ll}
\hline Laser wavelength & $1.54 \mu \mathrm{m}$ \\
\hline Ranging & CW focusing \\
\hline $\begin{array}{l}\text { Horizontal wind } \\
\text { retrieval }\end{array}$ & VAD scan \\
\hline Firmware & 2.1027 ZP300 \\
\hline Measuring heights & $\begin{array}{l}11,20,39,80,140,200,252 \mathrm{~m} \text { a.g.l. } \\
\text { (from 29 May 2019 also 60, 100, } \\
180 \text { and 300 m) }\end{array}$ \\
\hline Scan dwell time & $1 \mathrm{~s}$ \\
\hline Height instrument & $1 \mathrm{~m}$ \\
\hline Meteorological station & AIRMAR WeatherStation 200WX \\
\hline
\end{tabular}

ware. There is a maximum of 10 user-configurable measuring heights, besides a pre-fixed height of $38 \mathrm{~m}$ above the instrument, which all are measured sequentially by changing the focus of the laser beam after each VAD scan. An overview of properties and settings of the deployed ZephIR 300 instrument is given in Table 1. The ZephIR 300 has an automatic wiper system that operates when it rains and which is also supplied with a washer pump to aid cleaning in the event that the top window is soiled.

The wind retrieval from the VAD scan is based on the assumption of a homogeneous wind field in the scanning cone at each measurement level. Being a $\mathrm{CW}$ focusing wind lidar, the probe length increases quadratically with height: at $10 \mathrm{~m}$ height above the instrument, the probe length is $0.07 \mathrm{~m}$, whereas at $200 \mathrm{~m}$ it is $30 \mathrm{~m}$. CW focusing wind lidars can be sensitive to clouds that are above the maximum range, as the contribution to the Doppler signal from clouds in the tail of the laser pulse profile can be comparable to the aerosol signal at the preselected focusing height (Smith et al., 2006). A cloud removal algorithm is used to correct for this effect, which involved a measurement at an additional higher altitude (Kindler et al., 2007; Courtney et al., 2008).

As a result of the homodyne detection, meaning that only the absolute value of the Doppler shift is measured and not the sign, there is a $180^{\circ}$ ambiguity in the measured wind direction, as well as a sign ambiguity in the vertical wind speed. To overcome this issue, the ZephIR 300 includes a meteorological station containing a sonic anemometer, which wind direction information is directly fed into the ZephIR 300 internal algorithm to decide on the true wind direction. This aspect will be further discussed below in Sect. 5.2.3. In addition, zero wind speed cannot be measured, as a small region around zero Doppler shift needs to be filtered out (Courtney et al., 2008). A more extensive introduction of the ZephIR 300 (and its predecessors) is given in Pitter et al. (2015). 

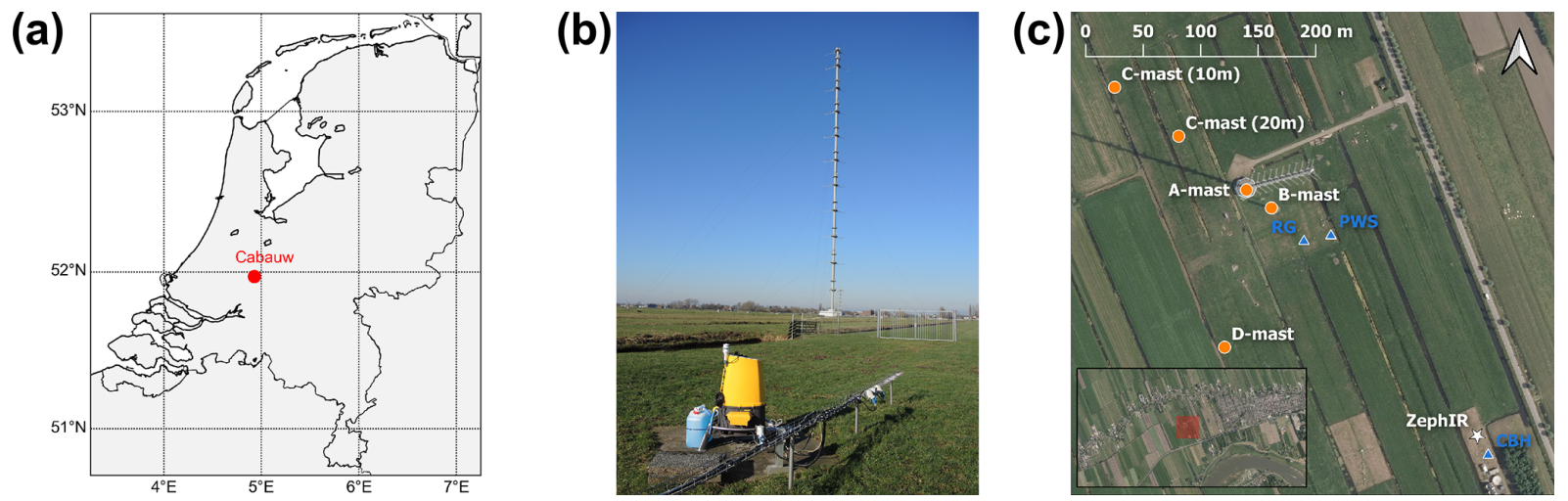

Figure 1. (a) Map of the Netherlands, indicating the location of measurement site near Cabauw $\left(51.971^{\circ} \mathrm{N}, 4.927^{\circ} \mathrm{E}\right)$. (b) Photo of the ZephIR 300 wind lidar instrument, with the $213 \mathrm{~m}$ tall A mast visible the background (view in NW direction). (c) Overview of the locations of the masts, the ZephIR wind lidar and other relevant instruments: rain gauge (RG), ceilometer (CBH) and present-weather sensor (PWS); the inset shows the area around the site (images from PDOK Landelijke Voorziening Beeldmateriaal, Luchtfoto 2019 Ortho $25 \mathrm{~cm}$ RGB).

The instrument reports, besides unaveraged data, qualitycontrolled (QC) 10 min averaged data, including horizontal and vertical wind speed; wind direction; minimum, maximum and standard deviation of the horizontal wind speed; and turbulence intensity. For wind speed, the mean is taken to derive the $10 \mathrm{~min}$ averaged data; for wind direction, vector averaging is applied. Reasons for not passing QC can be a very low wind speed event $\left(<1 \mathrm{~ms}^{-1}\right)$, partial obscuration of the window or significant interference with the laser beam at the specified height or atmospheric conditions which adversely affect lidar wind speed measurements. The analysis in this paper is based on these QC $10 \mathrm{~min}$ averaged data and is focused on the horizontal wind speed and wind direction.

Note that here the marine version of the ZephIR 300, ZephIR $300 \mathrm{M}$, is used, because this measurement campaign is related to offshore deployment. However, there is no difference in functionality or performance between these versions. Throughout this paper, we will address the instrument as ZephIR 300.

\section{Measurement site}

The Cabauw Experimental Site for Atmospheric Research (CESAR) is located in an extended and flat polder landscape, $0.7 \mathrm{~m}$ below mean sea level $\left(51.971^{\circ} \mathrm{N}, 4.927^{\circ} \mathrm{E}\right.$; see Fig. 1a). The site is centred around the $213 \mathrm{~m}$ research tower ("A mast") as shown in Fig. 1b, from which the atmospheric boundary layer can be sampled at various altitudes. Close to the tower is a platform with ground-based remote sensing instruments for vertical profiling and column-integrated observations, a platform for radiation measurements and a platform for monitoring of the energy balance (land-atmosphere interaction). Together, the instruments in the tower and the surrounding platforms constitute a comprehensive suite for atmospheric monitoring and process studies. The Cabauw site is a National Facility of ACTRIS ${ }^{1}$ (Aerosol, Clouds and Trace Gases Infra-Structure) and ICOS $^{2}$ (Integrated Carbon Observation System) and is the main site for the Ruisdael Observatory $^{3}$. An overview of 50-year Cabauw observations and research is given in Bosveld et al. (2020).

Wind speed and wind direction are measured with KNMI cup anemometers and KNMI wind vanes, respectively, at six levels $(10,20,40,80,140$ and $200 \mathrm{~m})$ using different masts (see Fig. 1c and Table 2). Precautions are taken to avoid toolarge flow obstruction from the A mast and the main building at the bottom of the A mast. At the levels of 40, 80, 140 and $200 \mathrm{~m}$ on the A mast, the wind direction is measured at three booms and wind speed is measured at two booms. Depending on wind direction, the best exposed sensors are chosen. At the levels of 10 and $20 \mathrm{~m}$, the wind direction and wind speed are measured at separate, smaller masts south ("B mast", SE from A mast) and north (two "C masts", NE from A mast for 20 and $10 \mathrm{~m}$ level, respectively) of the main building; the selection between these two masts depends on the wind direction. The wind data are quality controlled, including corrections for remaining flow distortions from the mast. In addition, another $10 \mathrm{~m}$ mast ("D mast", south of A mast) is present. For the $\mathrm{C}$ and $\mathrm{D}$ masts, the cup and vane are attached on top of masts, such that flow corrections are not needed.

The KNMI cup anemometer contains a photochopper with 32 slits. The sensitivity is $1.98 \mathrm{~m}$ of air per rotation, which results in $62 \mathrm{~mm}$ air passed per pulse. The distance constant is $2.9 \pm 0.4 \mathrm{~m}$. The cup anemometer measures the length of the wind vector. The accuracy of the cup anemometer is $1 \%$, or $0.1 \mathrm{~m} \mathrm{~s}^{-1}$ for low wind speeds. The cup anemometers are calibrated over a wind speed range of 2 to $20 \mathrm{~m} \mathrm{~s}^{-1}$. At higher wind speeds, the calibration of the cup anemometer may be slightly non-linear, the main reason being deformation of the

\footnotetext{
${ }^{1}$ http://actris.net/ (last access: 13 January 2021)

${ }^{2}$ https://www.icos-cp.eu/ (last access: 13 January 2021)

${ }^{3}$ https://ruisdael-observatory.nl/ (last access: 13 January 2021)
} 
Table 2. Overview of other meteorological instruments used in this study (RSS: remote sensing site, AWS: automatic weather station), their locations are also indicated in Fig. 1c.

\begin{tabular}{lllrr}
\hline Measurement & Location & Instrument & Height & Distance to wind lidar \\
\hline Wind speed/direction & A mast & KNMI cup anemometers/wind vanes & $40,80,140,200 \mathrm{~m}$ & $293 \mathrm{~m}$ \\
& B mast & & $10,20 \mathrm{~m}$ & $267 \mathrm{~m}$ \\
& C mast & $10 \mathrm{~m}$ & $437,367 \mathrm{~m}$ \\
& D mast & & $233 \mathrm{~m}$ \\
\hline Visibility & A mast & Biral SWS100 & $40,80,140,200 \mathrm{~m}$ & $29,10,20 \mathrm{~m}$ \\
& B mast & & $267 \mathrm{~m}$ \\
\hline Precipitation intensity & AWS & KNMI rain gauge & $226 \mathrm{~m}$ \\
\hline Cloud base height & RSS & Lufft CHM15K ceilometer & $19 \mathrm{~m}$ \\
\hline Present weather and visibility & AWS & Vaisala FD12P & $2 \mathrm{~m}$ & $215 \mathrm{~m}$ \\
\hline
\end{tabular}

cups. However, this effect will only give gradual deviations with increasing wind speed above $20 \mathrm{~m} \mathrm{~s}^{-1}$ (see Fig. 12 of Wauben, 2007). During operation, the comparability of the cup anemometers is monitored to stay within $1 \%$ by comparing the two available instruments at the same height, provided that wind direction allows for proper wind measurements for both. Calibration period for the cup anemometer is 14 months. The $10 \mathrm{~min}$ averaged wind speeds are calculated from the pulses counted in the $10 \mathrm{~min}$ period.

The cup anemometer is calibrated in the laminar flow of a wind tunnel. In a turbulent flow, as is often encountered in the atmosphere, overspeeding occurs because the response time of the instrument is proportional to the wind speed. Vertical fluctuations in the flow will also lead to overspeeding as the open sides of the cups will be better exposed to the wind. Following Kristensen (1993), we estimate overspeeding for the KNMI cup anemometer and for neutral conditions as $1.5 \%$ at $10 \mathrm{~m}, 0.9 \%$ at $20 \mathrm{~m}, 0.6 \%$ at $40 \mathrm{~m}, 0.4 \%$ at $80 \mathrm{~m}, 0.3 \%$ at $140 \mathrm{~m}$ and $0.3 \%$ at $200 \mathrm{~m}$. These values will be larger under unstable stratification and lower under stable stratification. No corrections are performed for overspeeding.

The KNMI wind vane contains a 8-bit code disc which results in a resolution of $1.5^{\circ}$. The damping ratio is 0.30 and the damped wave length is $7.0 \mathrm{~m}$. Accuracy of the vane depends on the instrument and on orientation of the vane plug. The vane fulfills the World Meteorological Organization (WMO) requirement of $3^{\circ}$. An overall check of the three vanes at each measurement level in the A mast suggests a comparability of $2^{\circ}$. Calibration period for the wind vane is 26 months. The wind direction is sampled at $4 \mathrm{~Hz}$ and decomposed as $x$ and $y$ components of the unit vector. The 10 min averaged wind direction is derived from the $10 \mathrm{~min}$ averages of the $x$ and $y$ components.

A KNMI automatic weather station (AWS) is located $100 \mathrm{~m} \mathrm{SE}$ of the A mast. The AWS includes, among other instruments, a KNMI electrical rain gauge that measures precipitation intensity and a Vaisala FD12P present-weather sensor that provides measurements of precipitation type and visibility (at a height of $2 \mathrm{ma.g.1}$.). The D mast is part of the AWS. Also part of the AWS, but located at the remote sensing site (RSS), is a Lufft CHM15K ceilometer, which reports the cloud base height (of maximally three cloud layers). In addition, Biral SWS-100 visibility sensors are located in the A mast (at 40, 80, 140 and $200 \mathrm{~m}$ ) and in the B mast (at 2, 10 and $20 \mathrm{~m}$ ). An overview of all relevant instruments, and their distances from the wind lidar, is given in Table 2. An updated description of the in situ observation programme in Cabauw is provided by Bosveld (2020).

\section{Measurement campaign}

The ZephIR 300 is placed at the northern part of the RSS of the Cabauw site, $290 \mathrm{~m}$ in SE direction from the A mast. The estimated accuracy of the alignment of the wind lidar instrument is about $1^{\circ}$. The instrument is configured to measure at (or close to) vertical levels of the mast wind measurements; see Table 1. Note that the minimum range of the ZephIR 300 is $10 \mathrm{~m}$ above the instrument, corresponding to a minimum height of $11 \mathrm{~m}$. Also, the pre-fixed height of $39 \mathrm{~m}$ a.g.l. does not allow us to select $40 \mathrm{~m}$ (as heights should be apart by at least $5 \mathrm{~m}$ ). The mast wind measurements are interpolated to match those wind lidar measurement levels (see Sect. 5.2). In Fig. 2, the wind conditions during the measurement campaign are shown: (a) the wind rose at a height of $10 \mathrm{~m}$ and (b) wind speed profile. The ZephIR 300 was operational from February 2018 until June 2020. The data considered here are from 15 February 2018 until 29 February 2020, covering more than 2 years. During the measurement campaign, two adjustments were made to the wind lidar. On 22 August 2018 , the meteorological station of the wind lidar was relocated to a separate pole (see Sect. 5.2.3) and on 29 May 2019 , the number of measuring levels of the wind lidar was extended from 7 to 11 . No maintenance (other than the automatic wiper system) was applied to the wind lidar during the full duration of the measurement campaign. 

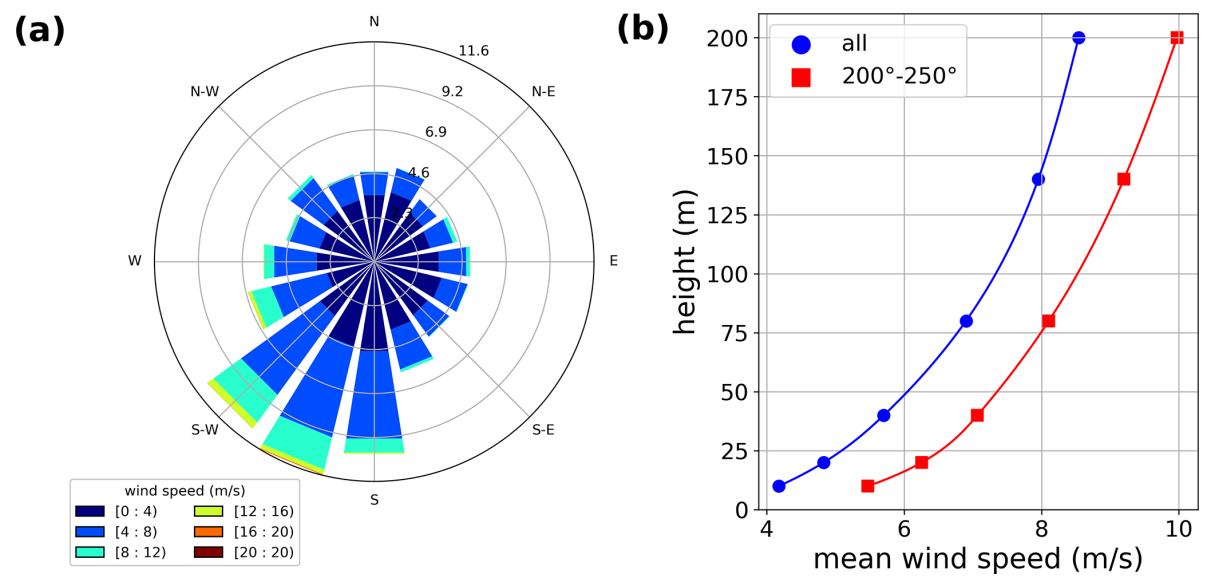

Figure 2. Wind conditions during the measurement campaign (15 February 2018 until 29 February 2020): (a) wind rose at $10 \mathrm{~m}$ height, (b) wind speed profiles for all wind directions and the wind sector between 200 and $250^{\circ}$. All are based on mast wind measurements.

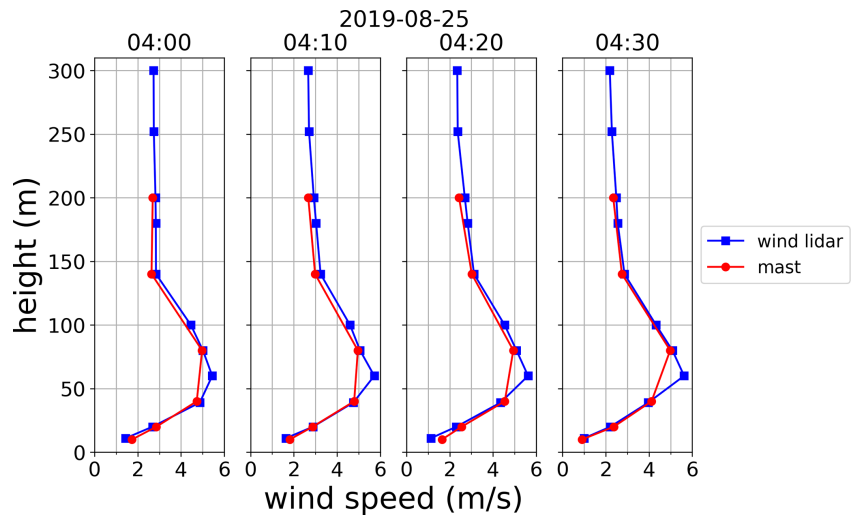

Figure 3. Example of a low-level jet in the early morning of $25 \mathrm{Au}-$ gust 2019, highlighting the benefit of more measuring levels provided by the wind lidar compared to the mast. The times (UTC) indicated at the top of the panels are the start of the $10 \mathrm{~min}$ interval.

The maximum amount of measuring heights available in the wind lidar exceeds that of the mast. As a result, the wind lidar can resolve the wind profile better than the mast. This is in particular relevant for non-monotonic wind profiles, of which low-level jets (LLJs) are the most prominent ones. In Fig. 3, an example of a LLJ is shown, following the criteria by Baas et al. (2009), where the wind lidar clearly captures the maximum wind speed of the LLJ much better than the mast measurements.

An example of a single-day comparison between the wind lidar and the mast is shown in Fig. 4. During this day (9 February 2020), when extratropical cyclone Ciara ${ }^{4}$ passed Cabauw, the mast measurements reported the highest reported wind speeds for all levels during the measurements campaign. The wind lidar and mast measurements are in

\footnotetext{
${ }^{4}$ also named Sabine in Germany or Elsa in the Scandinavian countries
}

close agreement for most of the levels, with the exception of some part of the day where the wind speed was around $25 \mathrm{~m} \mathrm{~s}^{-1}$ or higher, occurring mostly at 140 and $200 \mathrm{~m}$. The intercomparison at high wind speeds will be further discussed in Sect. 5.2.1.

\section{Results}

\subsection{Data availability}

The wind lidar was operating $99.4 \%$ of the time, with the most significant downtime during 26-29 July 2019, due to a full internal storage issue of the wind lidar. In the following, we consider data availability with respect to the uptime of the wind lidar. In Fig. 5a, the overall availability of the QC $10 \mathrm{~min}$ averaged wind data is shown by the filled bars, which ranges between $96.8 \%$ and $98.4 \%$. The wind speed distribution of the $2 \%$ to $3 \%$ of missing wind lidar data is shown in Fig. 5b. The lowest wind speed class $\left(<4 \mathrm{~m} \mathrm{~s}^{-1}\right)$ shows the largest reduction in QC data, especially for the upper levels, while for moderate wind speeds $\left(8-16 \mathrm{~m} \mathrm{~s}^{-1}\right)$ the reduction is the least.

In Fig. 5a, also the availability under "fair weather" conditions are given (open bars), which are very close to $100 \%$. Fair weather is defined here as no precipitation, visibility at $2 \mathrm{~m}$ in terms of meteorological optical range (MOR) more than $5 \mathrm{~km}$ and first cloud base height more than $1 \mathrm{~km}$, which accounts for $58 \%$ of the data. We will now take a closer look at the possible meteorological conditions that cause the decrease in QC data. Note that the meteorological data considered here are also $10 \mathrm{~min}$ averaged.

In Fig. 6a and b, the QC data availability is shown for different classes of precipitation intensity (as measured by the rain gauge) and presence of fog or low clouds (based on visibility measurements in the mast), respectively. The occurrences of the classes are given by the percentages be- 

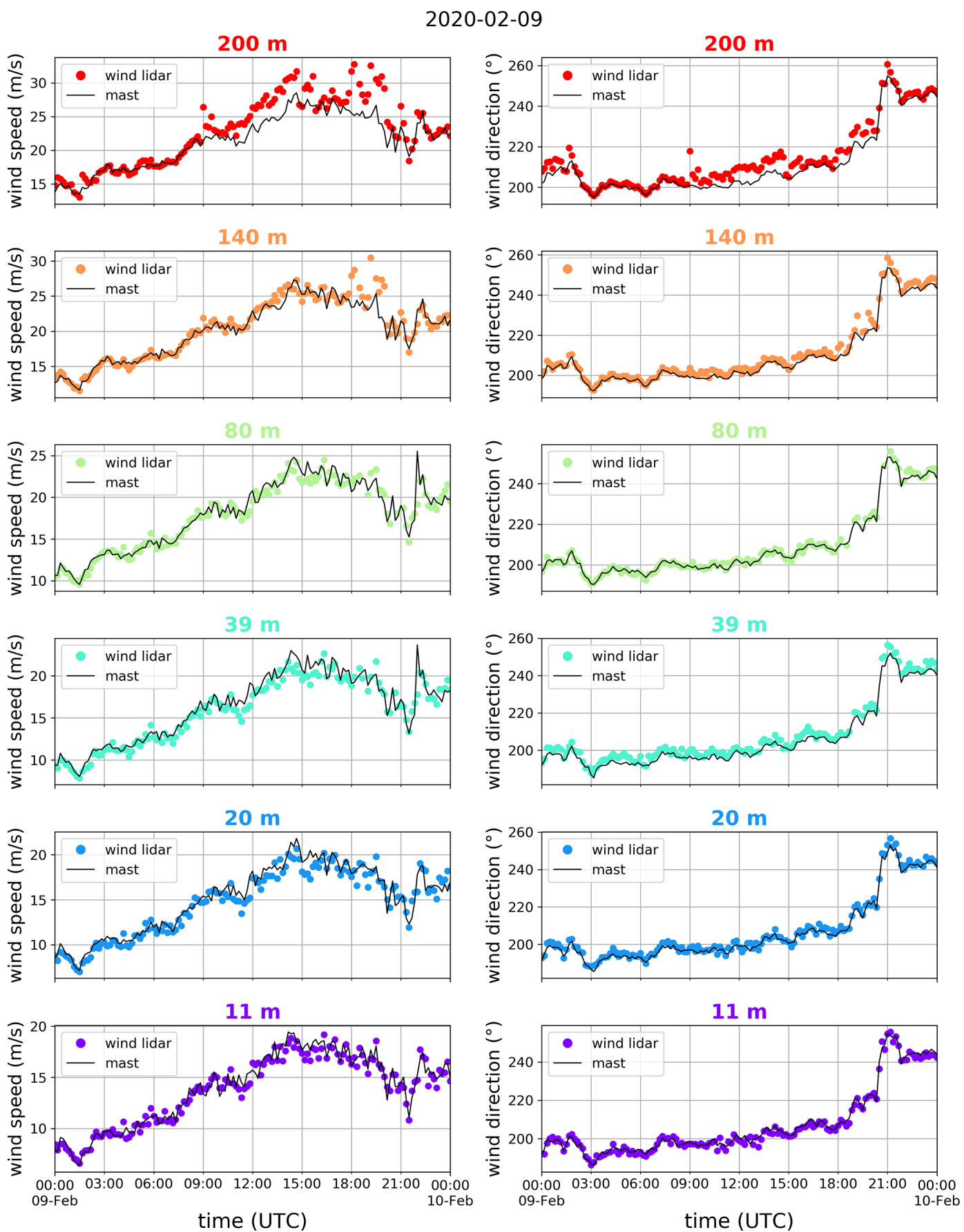

Figure 4. Wind measurements of 9 February 2020 (storm Ciara), comparing the 10 min averaged data of the mast (solid black lines) and the wind lidar (coloured symbols), showing wind speed (left) and wind direction (right) for different heights (indicated at the top of each panel).

tween brackets. The different measuring heights are indicated by the colours. We notice that light precipitation, up to $0.1 \mathrm{~mm} \mathrm{~h}^{-1}$, hardly affects the QC data availability. Only from an intensity of $1 \mathrm{~mm} \mathrm{~h}^{-1}$ onwards do we observe a significant reduction but mostly for the lower measuring heights. This is related to the height-dependent probe length. At the lower levels (short probe lengths), individual hydrom- eters can cause huge fluctuations in the return signal strength, which can have a detrimental impact on the wind retrieval. At the upper levels (long probe lengths), individual hydrometers are not resolved.

It is well known that low clouds and fog can limit the wind lidar performance due to the attenuation of the laser light. Here, we have defined the fog/low clouds classes on basis 
(a)

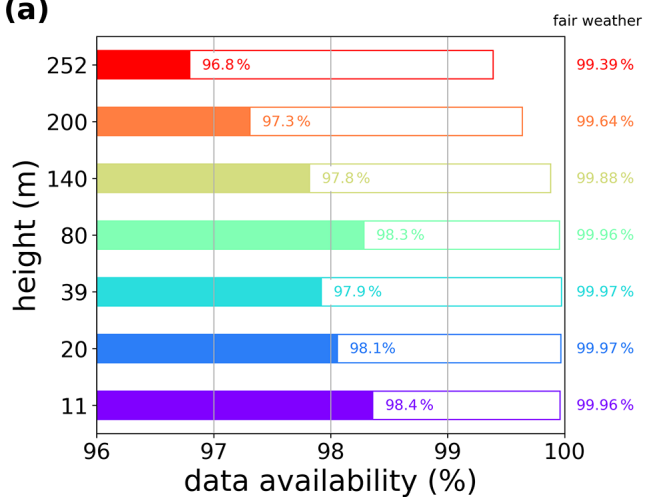

(b)

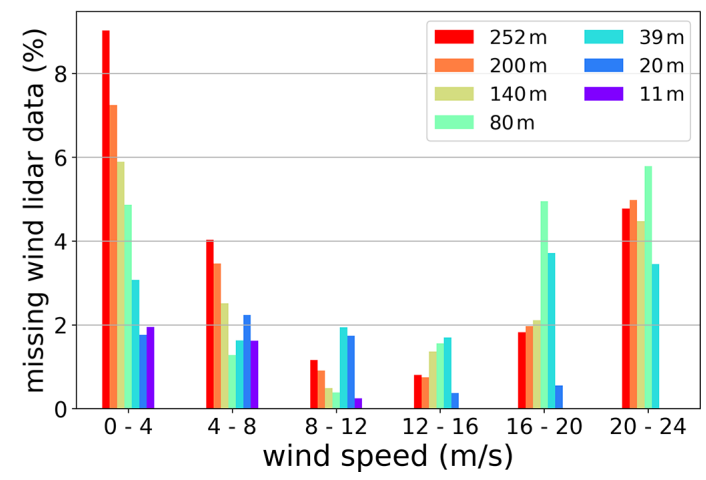

Figure 5. (a) Overall availability of QC wind lidar data for different vertical levels during the full uptime of the instrument (closed bars) and for "fair weather" conditions (open bars). (b) Percentage of missing wind lidar data for different wind speed classes based on the mast measurements at the corresponding levels. For the $252 \mathrm{~m}$ wind lidar level, mast wind speed measurements at $200 \mathrm{~m}$ are taken.

(a)

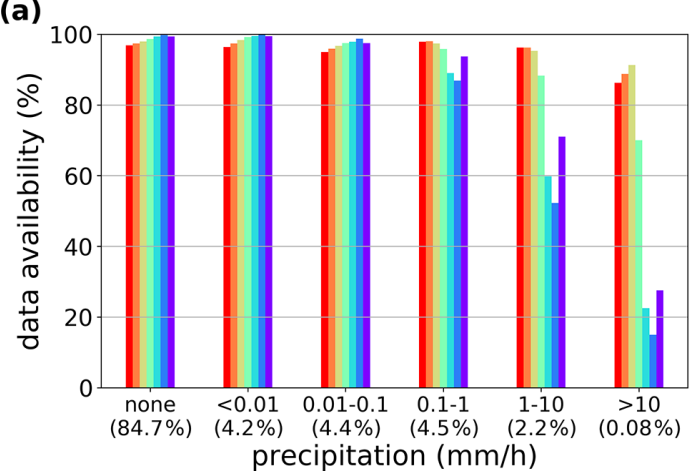

(b)

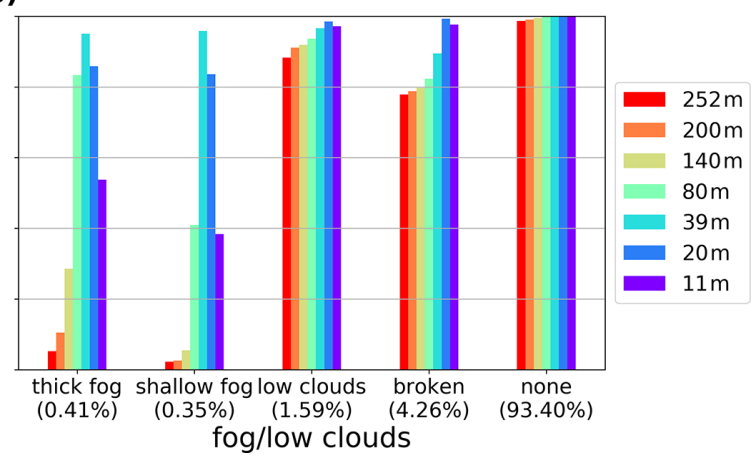

Figure 6. QC data availability of the wind lidar for (a) different classes of precipitation intensity and (b) presence of fog or low clouds (in the absence of precipitation). The colours indicate the measuring heights (see legend). Percentages between brackets are the occurrences of the classes.

on the visibility measurements in the A and B masts, which are performed at seven levels from 2 to $200 \mathrm{~m}$ (see Table 2). Events with precipitation are filtered out. The presence of fog (or clouds) at a certain level is triggered by visibility (MOR) less than $1 \mathrm{~km}$. The (mutually exclusive) classes are

- thick fog: fog at all levels;

- shallow fog: fog up to $80 \mathrm{~m}$ height (but not at all of the higher levels);

- low clouds: fog at 140 and $200 \mathrm{~m}$ (but not at all of the lower levels);

- broken: fog at least at one level (but not fitting in one of the previous classes);

- none: no fog at any level.

We observe that fog in the lower $100 \mathrm{~m}$ (thick and shallow fog) has a detrimental impact on the QC data availability of the upper measuring levels. As fog is typically correlated with low wind speeds, this also explains the relative large reduction of QC data for low wind speeds, as shown in Fig. 5b.
Interestingly, QC data availability at the moderate levels remains high, even under thick fog conditions. Clouds above $100 \mathrm{~m}$ do not have much impact. The reason why the low cloud class has more QC data for the upper measuring levels than the broken class might be due to enhanced backscatter from the cloud base compensating the attenuation below the clouds.

The analysis based on the visibility measurements in the mast is consistent with that of the first cloud base height derived from the ceilometer ${ }^{5}$. We observed that from a $\mathrm{CBH}$ of $100 \mathrm{~m}$ or higher, the impact on amount of QC data is small, with the higher measuring heights being more affected, but still above $90 \%$ even if measuring height is above $\mathrm{CBH}$. Below a CBH of $100 \mathrm{~m}$, the amount of QC data is significantly reduced for measuring heights of $80 \mathrm{~m}$ and higher.

\footnotetext{
${ }^{5}$ The Lufft CHM15K ceilometer was operating at firmware v0.747 or higher in combination with a "low cloud detection mode" during the measurement campaign.
} 


\subsection{Data quality}

We assess the data quality of the wind lidar by a comparison with the cup anemometers and wind vanes in the masts. Wind measurements are sensitive to local obstacles, such a (rows of) trees, in particular for the lower levels. This limits the correlation between measurements at different locations. The distances between the wind lidar and the masts are relatively large, up to a few hundred metres (see Table 2). Therefore, several measures have been taken to create a fair comparison. This includes considering only the nearest mast for the $10 \mathrm{~m}$ wind (D mast), omitting the $20 \mathrm{~m}$ mast wind as this is measured by the further away B and C masts, and selecting only data from the $200-250^{\circ}$ wind sector, which has a long free stream (van Ulden and Wieringa, 1996; Verkaik and Holtslag, 2007). The latter also circumvents the effect of the constructions on the RSS south to the wind lidar and trees on the east side of RSS (see Figs. 1c and 15b). Note that the selected wind sector overlaps with the prevailing wind direction (see Fig. 2a), and still $22 \%$ of the data are present in the data quality analysis.

The following steps are taken to construct the "reference" mast wind data set:

1. Take the original Cabauw $10 \mathrm{~min}$ averaged, qualitycontrolled wind speed and direction (10, 20, 40, 80, 140 and $200 \mathrm{~m}$ ), based on measurements from the A, B and C masts ("original mast wind data set").

2. Interpolate (cubic spline) each wind profile of the original mast wind data set to obtain a 11 and $39 \mathrm{~m}$ mast wind speed and direction (forming the "extended original mast wind data set").

3. Take the $10 \mathrm{~min}$ averaged D-mast wind speed and direction $(10 \mathrm{~m})$.

4. Derive a $11 \mathrm{~m} \mathrm{D}$-mast wind speed by rescaling the $10 \mathrm{~m}$ D-mast wind speed by the extended original mast wind data set $11 \mathrm{~m} / 10 \mathrm{~m}$ wind speed ratio.

5. Derive a $11 \mathrm{~m}$ D-mast wind direction by adding the difference between the 11 and $10 \mathrm{~m}$ wind direction in the extended original mast wind data set to the $10 \mathrm{~m}$ D-mast wind direction.

6. Combine the $11 \mathrm{~m} \mathrm{D}$-mast wind with the extended original mast wind data set at 39, 80, 140 and $200 \mathrm{~m}$, omitting $20 \mathrm{~m}$.

7. Select wind sector between 200 and $250^{\circ}$, based on $10 \mathrm{~m}$ wind from the D mast.

8. Select wind speeds larger than $0.5 \mathrm{~m} \mathrm{~s}^{-1}$.

In Appendix A, a comparison of the results from different wind sectors is provided. For the lower levels (up to $39 \mathrm{~m}$ ), differences are indeed observed, with the free-stream wind sector $\left(200-250^{\circ}\right)$ showing the "best" comparison. For the upper levels (from $80 \mathrm{~m}$ onwards), the main results are mostly independent from the chosen wind sector. However, to be consistent, we have applied the wind sector selection to all levels.

\subsubsection{Horizontal wind speed}

The horizontal wind speed data of the wind lidar and the mast measurements are compared for five heights. Scatter plots are presented in Fig. 7. Linear regression fits are shown and the correlation coefficient $R^{2}$ is provided. In addition, the mean bias and standard deviation are given. Bias is defined as the wind lidar wind speed minus mast wind speed. For visualization purposes, the scatter plots are presented as density plots with finite bin sizes, with a logarithmic colour scale. The fits and biases are related to the individual data points. For the linear regression, we find the slope ranging from 0.99 to 1.00 with $R^{2}$ better than 0.995 . The mean bias is between -0.08 and $0.02 \mathrm{~m} \mathrm{~s}^{-1}$, and the standard deviation is between 0.4 and $0.8 \mathrm{~m} \mathrm{~s}^{-1}$. These results are considering the full wind speed range.

Within the wind energy industry wind lidars are typically validated only between 4 and $16 \mathrm{~m} \mathrm{~s}^{-1}$, while from a meteorological point of view lower and higher wind speeds are also of interest. In Fig. 8, results of linear regression and the biases for three different wind speed classes $(2-4,4-16,16-$ $20 \mathrm{~m} \mathrm{~s}^{-1}$ ) are shown. The results for the $4-16 \mathrm{~m} \mathrm{~s}^{-1}$ class: slope ranging from 0.99 to 1.00 with $R^{2}$ better than 0.996 ; mean bias between -0.10 and $-0.07 \mathrm{~m} \mathrm{~s}^{-1}$, standard deviation between 0.4 and $0.6 \mathrm{~m} \mathrm{~s}^{-1}$. These results are similar to the ones shown in Fig. 7 based on the full wind speed range.

For lower wind speeds $\left(2-4 \mathrm{~m} \mathrm{~s}^{-1}\right)$, the slope deviates more from 1 and the correlation is smaller compared to the $4-16 \mathrm{~m} \mathrm{~s}^{-1}$ class. Here, the mean bias is slightly positive, between 0.03 and $0.13 \mathrm{~m} \mathrm{~s}^{-1}$. A positive bias for low wind speeds has been reported (Courtney et al., 2008), which was related to the inability of the homodyne wind lidar to measure zero Doppler shift. However, we have found that the wind lidar reported wind speeds down to $0.6 \mathrm{~m} \mathrm{~s}^{-1}$, much lower than the minimum wind speed in this class. We note that the accuracy of the cup anemometer is $0.1 \mathrm{~m} \mathrm{~s}^{-1}$ in this wind speed region, which is of the same order as the observed mean bias.

For higher wind speeds $\left(16-20 \mathrm{~m} \mathrm{~s}^{-1}\right)$, larger deviations are observed, and the bias varies from -0.5 to $0.5 \mathrm{~m} \mathrm{~s}^{-1}$ with measuring height. For even higher wind speeds $\left(>20 \mathrm{~m} \mathrm{~s}^{-1}\right)$, visual inspection of Fig. 7 indicates a positive bias and large scatter for 140 and $200 \mathrm{~m}$. This feature was already noted in the example presented in Fig. 4. As discussed above, possible non-linearity of the cup anemometer calibration above $20 \mathrm{~m} \mathrm{~s}^{-1}$, which indeed would give a positive bias, only will give a gradual deviation with increasing wind speed and cannot explain these large differences between the wind lidar and the mast measurements. 
(a)

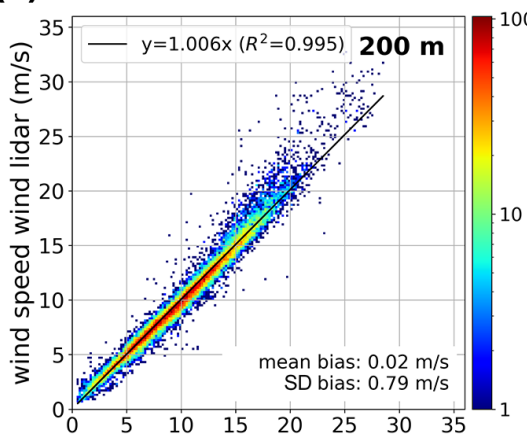

(d)

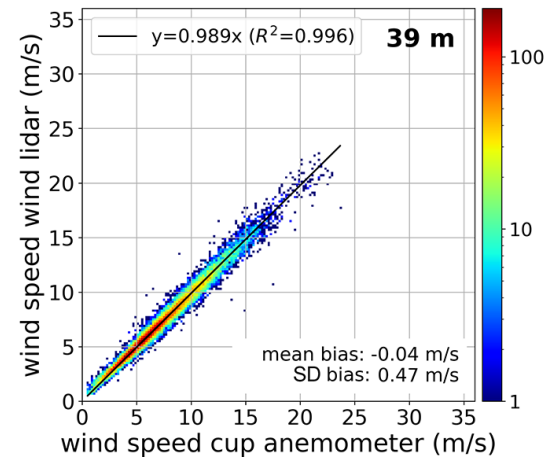

(b)

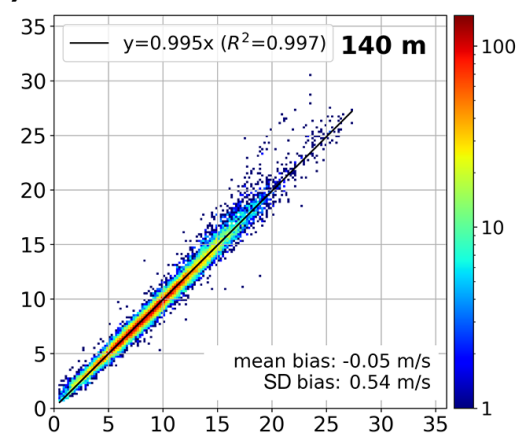

(c)

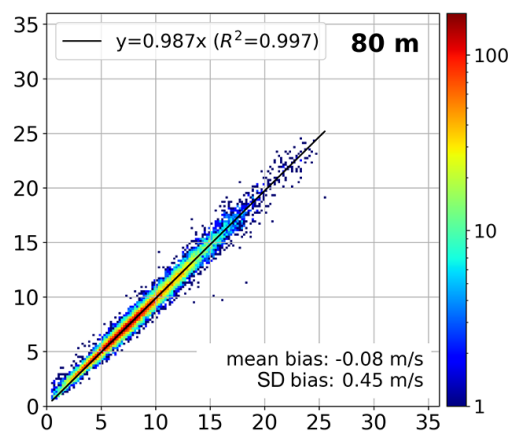

(e)

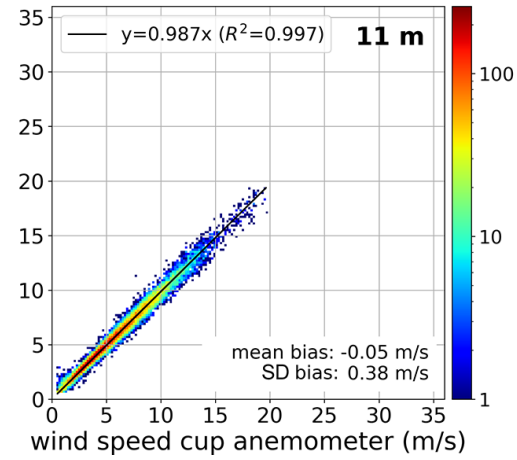

Figure 7. Wind speed comparison between wind lidar and mast data for the different heights: (a) $200 \mathrm{~m}$, (b) $140 \mathrm{~m}$, (c) $80 \mathrm{~m}$, (d) $39 \mathrm{~m}$ and (e) $11 \mathrm{~m}$. The results of a linear regression analysis and the mean bias and standard deviation in the bias are indicated in each panel.

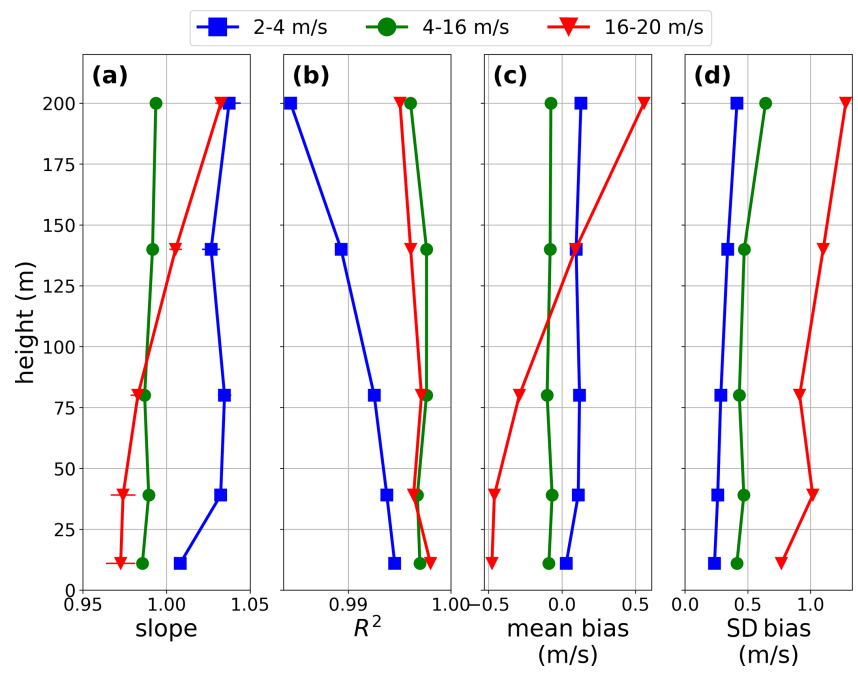

Figure 8. Profiles of linear regression analysis results and biases in the wind speed, applied to three different wind speed classes: 2$4 \mathrm{~m} \mathrm{~s}^{-1}$ (blue squares), 4-16 $\mathrm{m} \mathrm{s}^{-1}$ (green circles) and 16-20 $\mathrm{m} \mathrm{s}^{-1}$ (red triangles). Panels $(\mathbf{a}, \mathbf{b})$ show the parameters from a linear regression (slope and $R^{2}$ ), and panels (c, $\mathbf{d}$ ) show the mean bias and standard deviation of the bias. The error bars in panel (a) indicate the standard uncertainties of the parameter estimates (often behind the symbol).
The co-located meteorological observations allow us to verify the QC wind lidar data for different weather conditions. In Fig. 9, results of linear regression and the biases are shown for "fair weather", "precipitation" and "fog/low clouds" conditions. "Fair weather" is defined as above (no precipitation, MOR $>5 \mathrm{~km}$ at $2 \mathrm{~m}$ and first cloud base height more than $1 \mathrm{~km}$ ); for "precipitation", a threshold of $0.1 \mathrm{~mm} \mathrm{~h}^{-1}$ is taken; and "fog/low clouds" requires at least one mast level with MOR $<1 \mathrm{~km}$, while precipitation events are filtered out. Here, wind speed is bounded to the 4 $16 \mathrm{~m} \mathrm{~s}^{-1}$ range for a more fair comparison, recognizing that different weather conditions may be connected to different typical wind speeds.

The fair weather condition gives overall the best results, while the possible impact of precipitation or fog/low clouds on the data quality is small. Most notable is a more negative mean bias at most measuring heights, up to $-0.3 \mathrm{~ms}^{-1}$ at $200 \mathrm{~m}$ for fog/low clouds. The presence of fog or low clouds might lead to more attenuation of the backscatter signal originating from the farther side of the focus point relative to the closer side, effectively lowering the measurement height and leading (on average) to smaller wind speeds as measured by the wind lidar.

Finally, the extended duration of the measurement campaign provides the possibility to investigate seasonal dependencies in, as well as long-term stability of, the performance 

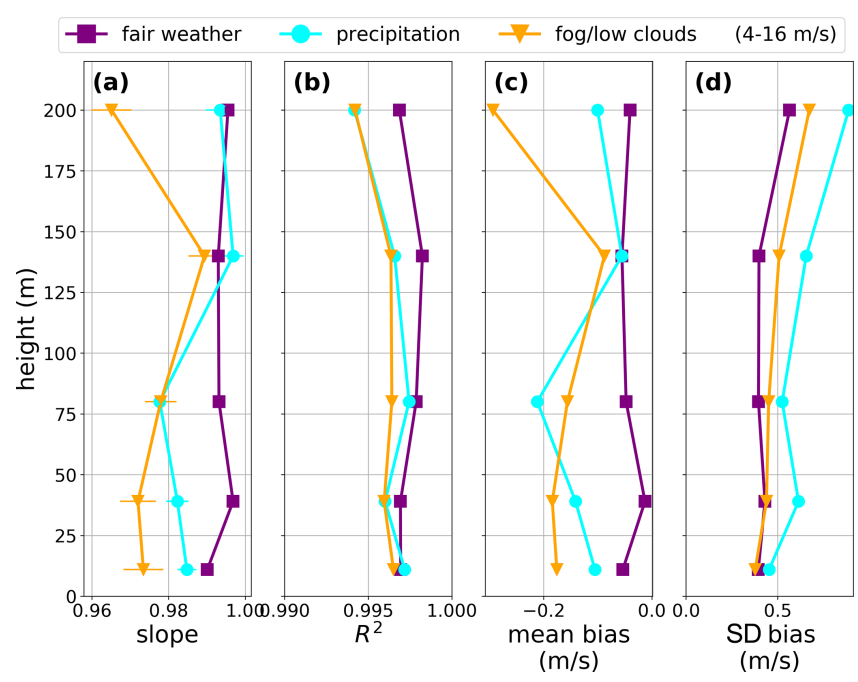

Figure 9. Profiles of linear regression analysis results and biases in the wind speed, applied to three different meteorological conditions: fair weather (purple squares), precipitation (cyan circles) and fog/low clouds (orange triangles). Here, wind speed is bounded to the $4-16 \mathrm{~m} \mathrm{~s}^{-1}$ range. Panels (a, b) show the parameters from a linear regression (slope and $R^{2}$ ), and panels $(\mathbf{c}, \mathbf{d})$ show the mean bias and standard deviation of the bias. The error bars in panel (a) indicate the standard uncertainties of the parameter estimates (often behind the symbol).
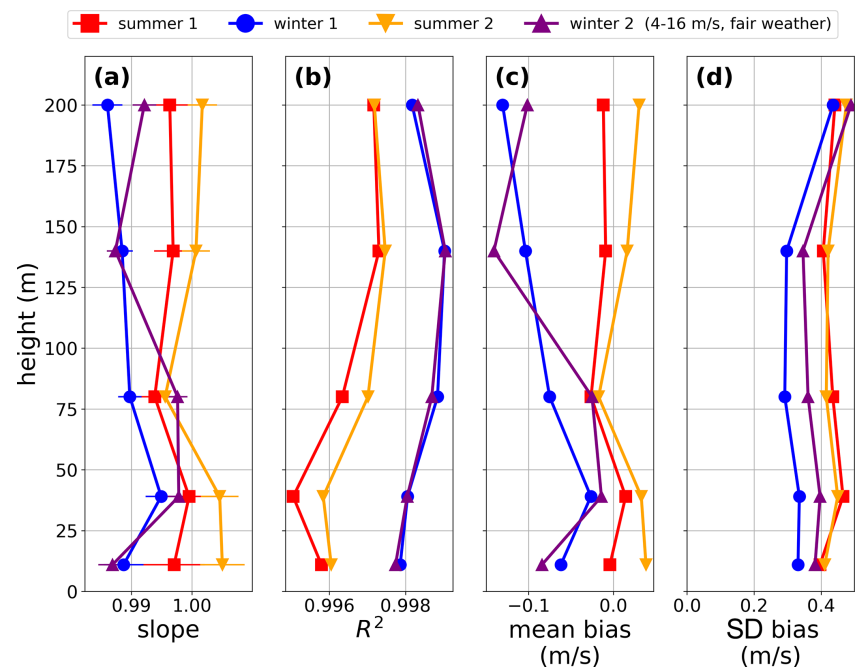

Figure 10. Profiles of linear regression analysis results and biases in the wind speed, applied to the two summers (June, July and August) and winters (December, January and February). Here, wind speed is bounded to the $4-16 \mathrm{~m} \mathrm{~s}^{-1}$ range and only fair weather conditions are taken. Panels $(\mathbf{a}, \mathbf{b})$ show the parameters from a linear regression (slope and $R^{2}$ ), and panels (c, d) show the mean bias and standard deviation of the bias. The error bars in panel (a) indicate the standard uncertainties of the parameter estimates.

of the wind lidar. In Fig. 10, results of linear regression and the biases are shown for the two summers (June, July and Au- gust) and winters (December, January and February). Here, the wind speed is bound to the $4-16 \mathrm{~m} \mathrm{~s}^{-1}$ range and only fair weather conditions are taken. We observe small but reproducible differences, with the mean bias in winter about $0.1 \mathrm{~m} \mathrm{~s}^{-1}$ more negative than in summer for the upper levels. An in-depth analysis of this effect, which includes the impact of all relevant environmental variables (such as temperature, air density, stability, turbulence intensity) on both the wind lidar and the cup anemometer measurements, is beyond the scope of this paper but will be subject to further study.

\subsubsection{Wind direction}

The wind direction data of the wind lidar and the mast measurements are compared for five heights. Scatter plots are presented in Fig. 11. The selected wind sector is between 200 and $250^{\circ}$, as measured at $10 \mathrm{~m}$. The mean bias and standard deviation are indicated. Bias is defined as the wind lidar wind direction minus mast wind direction. For visualization purposes, the scatter plots are presented as density plots with finite bin sizes, with a logarithmic colour scale. The biases are related to the individual data points. The presence of data points around $\pm 180^{\circ}$ away from the $y=x$ line will be discussed in Sect. 5.2.3. Here, only the wind lidar data for which the difference with the mast is less than $90^{\circ}$ are taken into account. We find values of the mean bias ranging from -0.4 to $1.9^{\circ}$, which is within the combined accuracy of the wind vanes and the alignment of the wind lidar. The standard deviation in the bias is between 4 and $6^{\circ}$.

In Fig. 12a and b, results of the bias for the three different wind speed classes $\left(2-4,4-16,16-20 \mathrm{~m} \mathrm{~s}^{-1}\right)$ are shown. The variation in the mean bias is within the combined accuracy of the wind vanes and the alignment of wind lidar. When considering wind speeds above $4 \mathrm{~m} \mathrm{~s}^{-1}$, the standard deviation is $3^{\circ}$ or less. For low wind speeds, the standard deviation in the bias is much larger, which is mainly a property of the wind field rather than the instruments.

In Fig. 12c and d, the biases are shown for "fair weather", "precipitation" and "fog/low clouds" conditions (as defined above), for which the wind speed is bounded to the 4$16 \mathrm{~m} \mathrm{~s}^{-1}$ range. Again, the variation in the mean bias is within the combined accuracy of the wind vanes and the alignment of wind lidar. Precipitation and fog/low clouds show a slight increase in the standard deviation towards higher levels, up to $7^{\circ}$.

We note that the method of deriving the $10 \mathrm{~min}$ wind direction averages differs between the wind lidar (wind vector averaging) and the mast measurements (unit vector averaging), which in principle could lead to slightly different results. However, we expect significant effects only for periods of very large wind direction variations, such as low wind speeds or convective situations, which are, for instance, unlikely to be present in the $4-16 \mathrm{~m} \mathrm{~s}^{-1}$ wind speed class. 
(a)

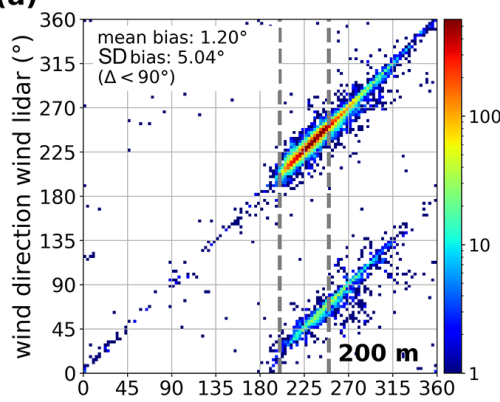

(b)

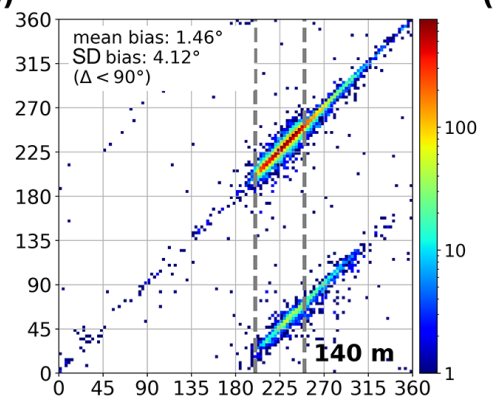

(c)

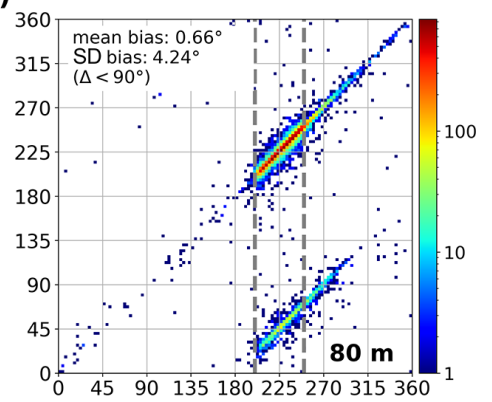

(d)

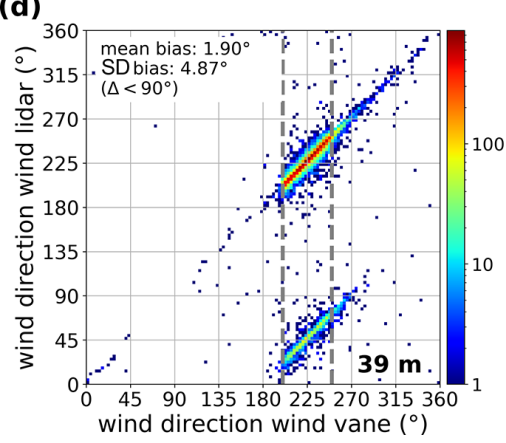

(e)

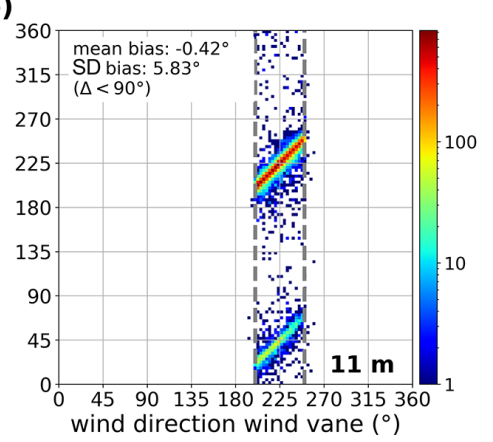

Figure 11. Wind direction comparison between wind lidar and mast data for the different heights: (a) $200 \mathrm{~m}$, (b) $140 \mathrm{~m}$, (c) $80 \mathrm{~m}$, (d) $39 \mathrm{~m}$ and (e) $11 \mathrm{~m}$. The mean bias and standard deviation in the bias are indicated in each panel, taking into account only data for which the deviation is less than $90^{\circ}$. Note that the selected wind sector of $200-250^{\circ}$ is based on the $10 \mathrm{~m}$ wind.

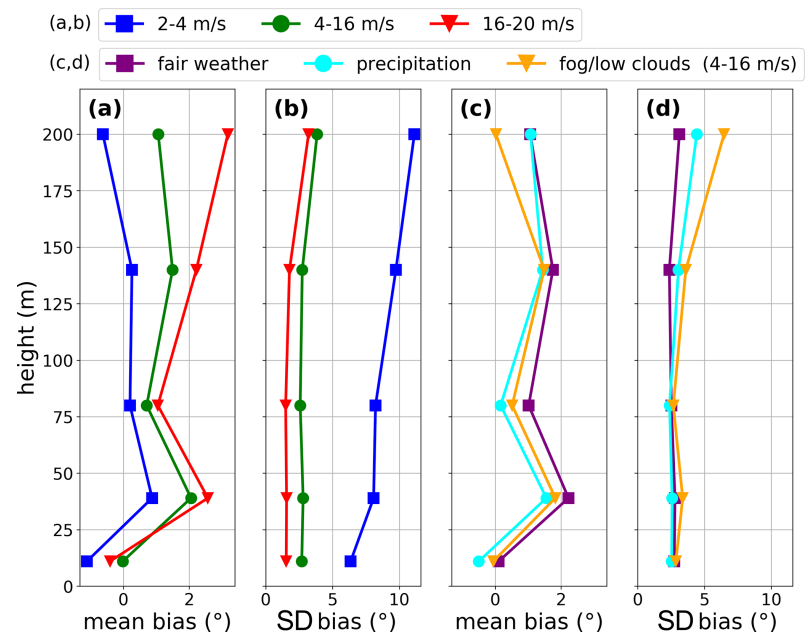

Figure 12. Profiles of the biases in the wind direction for different wind speed classes and meteorological conditions. Panels $(\mathbf{a}, \mathbf{b})$ show the mean bias and standard deviation of the bias applied to three different wind speed classes: $2-4 \mathrm{~ms}^{-1}$ (blue squares), 4-16 $\mathrm{m} \mathrm{s}^{-1}$ (green circles) and $16-20 \mathrm{~m} \mathrm{~s}^{-1}$ (red triangles). Panels (c, d) show the mean bias and standard deviation of the bias applied to three different meteorological conditions (and wind speed is bounded to the $4-16 \mathrm{~m} \mathrm{~s}^{-1}$ range): fair weather (purple squares), precipitation (cyan circles) and fog/low clouds (orange triangles).

\subsection{3 $180^{\circ}$ ambiguity}

The ZephIR 300 instrument is based on homodyne detection, meaning that only the absolute value of the Doppler shift is measured. As a result, there is a $180^{\circ}$ ambiguity in the measured wind direction. To solve this issue, the ZephIR 300 includes an attached meteorological station, which contains a sonic anemometer to measure the wind direction just above the instrument, i.e. a height of $1 \mathrm{~m}$. This information is used in the instrument's internal algorithm to determine the true wind direction of the wind lidar measurements. Still, the occurrence of incorrectly assigned wind direction events is possible, resulting in part from the wind direction data that are off by $180^{\circ}$. This is most likely in situations of very low wind conditions, in which wind direction is not very well defined, but can also be caused by nearby obstructions that alter the wind flow at the location of the meteorological station.

The incorrectly assigned wind direction events can be observed $180^{\circ}$ off from the $y=x$ line in Fig. 11. For many applications, it is sufficient to correct the wind direction data offline. However, for real-time applications, such as nowcasting, it would be desirable to (1) minimize their occurrence and (2) correct in real time. Here, we have compared two positions of the meteorological station and considered a correction scheme based on mast wind direction information at a single level. 

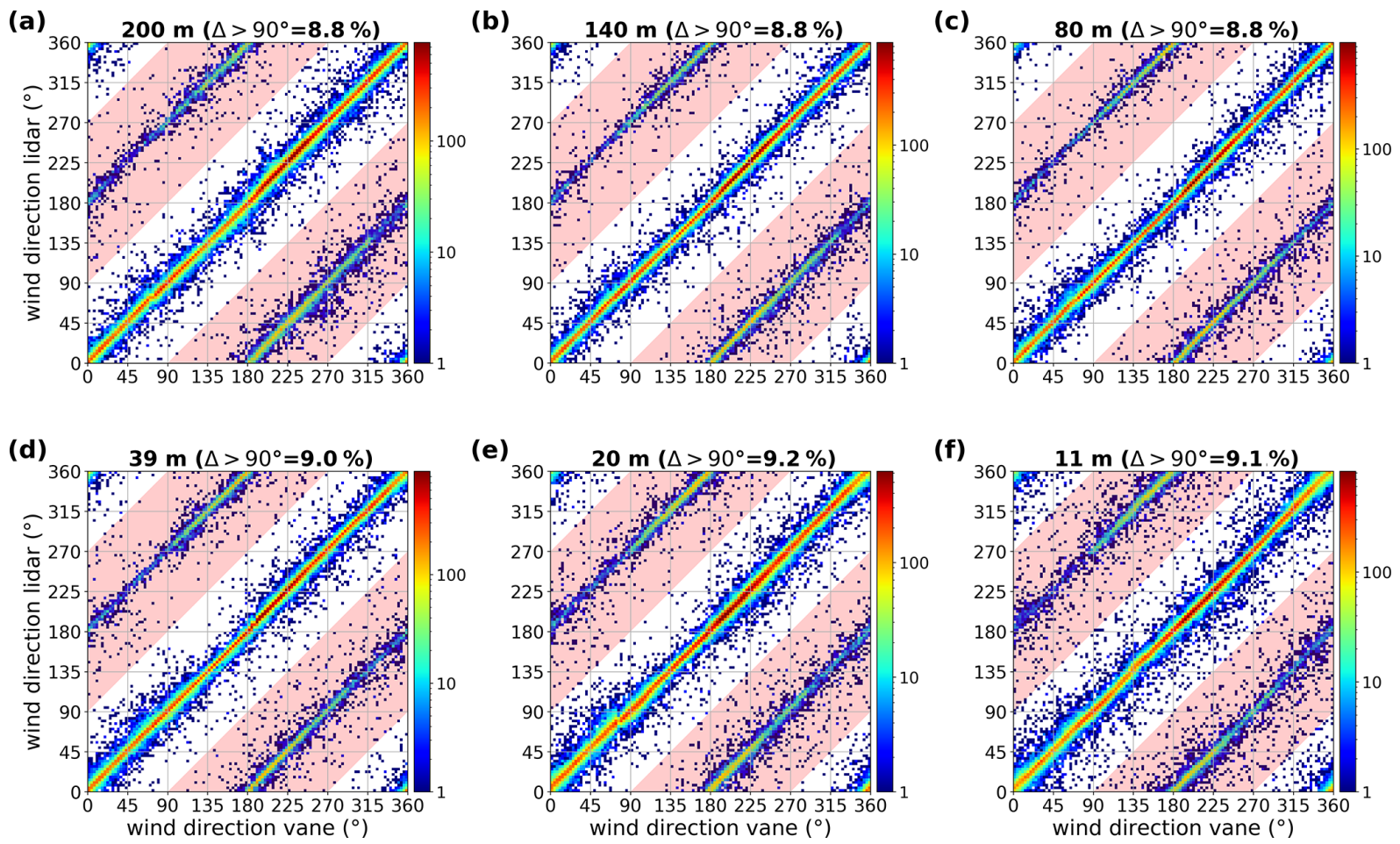

Figure 13. Wind direction comparison between wind lidar and mast data for the different heights: (a) $200 \mathrm{~m}$, (b) $140 \mathrm{~m}$, (c) $80 \mathrm{~m}$, (d) $39 \mathrm{~m}$, (e) $20 \mathrm{~m}$ and (f) $11 \mathrm{~m}$. Compared to Fig. 11, here all wind directions at the $20 \mathrm{~m}$ level are included. The regions of incorrectly assigned wind direction are indicated in red; the percentages of data in those areas are indicated at the top of each panel.

In order to quantify the occurrence of incorrectly assigned wind direction, we consider events for which the absolute difference between the wind lidar and the wind vane (at the same measuring height), denoted $\Delta$, is more than $90^{\circ}$ $\left(\Delta>90^{\circ}\right)^{6}$. This is motivated by the observation of clearly separate "groups" of data around the $y=x$ and $y=x \pm 180^{\circ}$ lines (i.e. the standard deviation in the bias is much smaller than $180^{\circ}$ ). We now take data from all wind directions, not only free-flow stream, and included $20 \mathrm{~m}$ height as accuracy is less crucial here. Figure 13 shows again scatter plots of the wind direction data but now including all wind directions and the $20 \mathrm{~m}$ level. The $\Delta>90^{\circ}$ events are located in the red-coloured regions; their percentages are shown above each panel, which is about $9 \%$, with little variation over the heights.

In Fig. 14a, the percentages of $\Delta>90^{\circ}$ events are also shown for the different heights. In addition, results for wind speeds above $4 \mathrm{~m} \mathrm{~s}^{-1}$ are shown, either related to wind speed measured at $10 \mathrm{~m}$ or at the corresponding height of the wind lidar measurements. First of all, omitting low wind speeds leads to a reduction of the $\Delta>90^{\circ}$ occurrences. Second, their occurrences are dependent on the wind speed near the instrument, rather than the measuring height of the wind lidar. This explains the moderate reduction at the highest lev-

\footnotetext{
${ }^{6}$ after folding the wind direction differences in the -180 to $180^{\circ}$ range
}

(a)

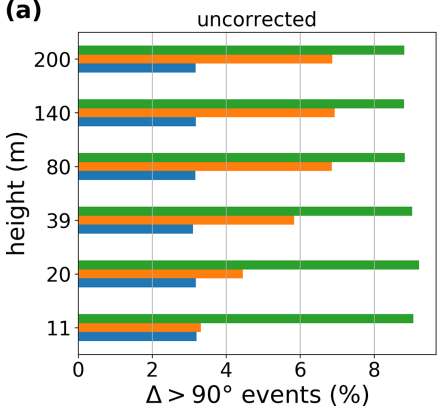

(b)

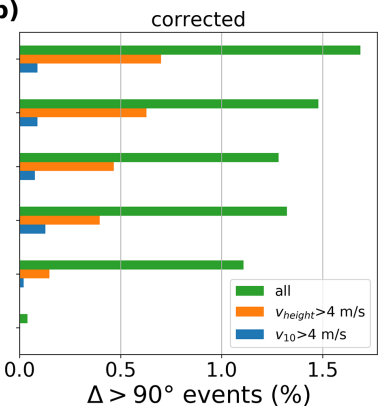

Figure 14. (a) Histogram of the $\Delta>90^{\circ}$ events for the different measuring heights, based on either all events (green), wind speeds larger than $4 \mathrm{~ms}^{-1}$ at the measuring height (orange) and $10 \mathrm{~m}$ (blue). Panel (b) is the same as (a) but after application of the correction scheme (see text), based on information from the $10 \mathrm{~m}$ mast wind vane.

els, for which wind speeds above $4 \mathrm{~ms}^{-1}$ still can be connected with much lower wind speeds near the surface.

The standard location of the meteorological station is directly on top of the ZephIR 300, as can be seen in Fig. 1b. However, it is possible (and in some cases recommended by the manufacturer) to install the meteorological station separately from the wind lidar, for instance, if the wind lidar is enclosed within (open) fences. We have relocated the mete- 

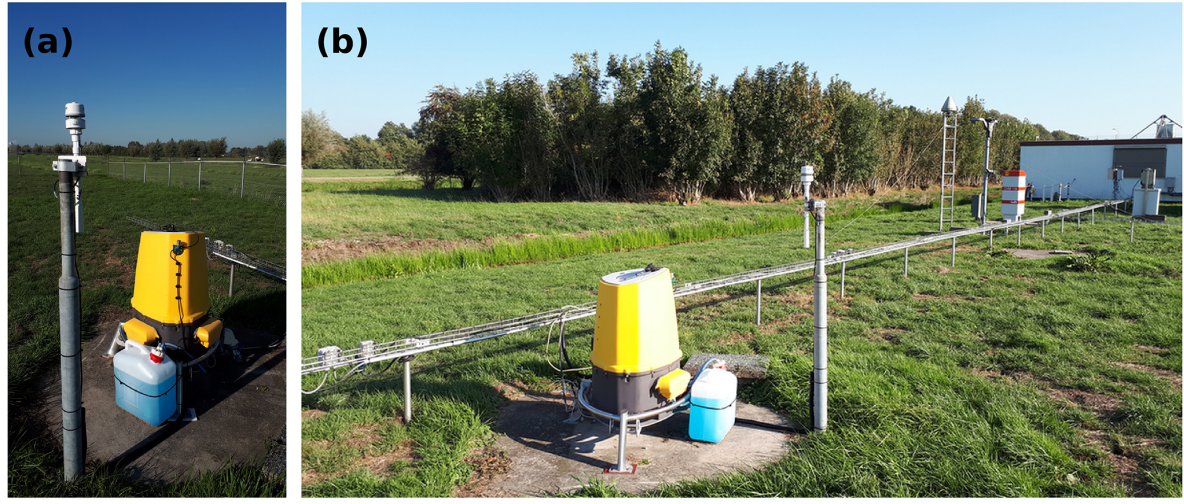

Figure 15. Photos of (a) the meteorological station of ZephIR 300 instrument located on a separate pole and (b) a view to the southeast direction, showing building on RSS and nearby trees.

orological station after 6 months of the measurement campaign to a separate pole, at a height of $1.5 \mathrm{~m}$ (see Fig. 15a), for the remaining 1.5 years.

In Fig. 16, we show the $\Delta>90^{\circ}$ occurrence for the lowest measuring height $(11 \mathrm{~m})$ for different wind sectors, separating the data regarding the location of the meteorological station. We see that the $\Delta>90^{\circ}$ occurrence depends on the wind direction, being much more prominent for southerly wind. This can be explained by the presence of buildings and large instruments at RSS and trees to the east side of RSS that disturb the wind flow at the meteorological station (see Fig. 15b). Again, when considering only wind speeds larger than $4 \mathrm{~m} \mathrm{~s}^{-1}$ (as measured at $10 \mathrm{~m}$ ), $\Delta>90^{\circ}$ drops significantly. We cannot explain the observation that $\Delta>90^{\circ}$ has occurred more often for the meteorological station on the separate pole than directly on the ZephIR 300 instrument.

The severity of how the $180^{\circ}$ issue is present in the wind lidar measurements depends on both wind speed and wind direction through the characteristics of its surroundings. The low height of the meteorological station means that low wind conditions can prohibit reliable wind direction measurements and being more sensitive to disturbance in the wind flow by nearby objects. The height increase from 1.0 to $1.5 \mathrm{~m} \mathrm{did} \mathrm{not}$ lead to a decrease of $\Delta>90^{\circ}$.

With additional (real-time) information about the actual wind direction, one can correct the $\Delta>90^{\circ}$ events. In the event that such information is only available at a single height, one can compare this with a corresponding or nearby height of the ZephIR 300, and each time $\Delta>90^{\circ}$ for this height occurs, change the ZephIR 300 wind direction data for all heights by $180^{\circ}$. In Fig. 14b, we show the result of such a correction on basis of the $10 \mathrm{~m}$ D-mast wind data. While the largest reduction is for the nearby height (by definition, $\Delta>90^{\circ}$ will be absent when these heights are equal), also the reduction for the other height is significant, with $\Delta>90^{\circ}$ drops from $9 \%$ to well below $2 \%$. When considering wind speeds above $4 \mathrm{~m} \mathrm{~s}^{-1}, \Delta>90^{\circ}$ is further reduced well below $1 \%$, depending on which height the wind speed threshold is

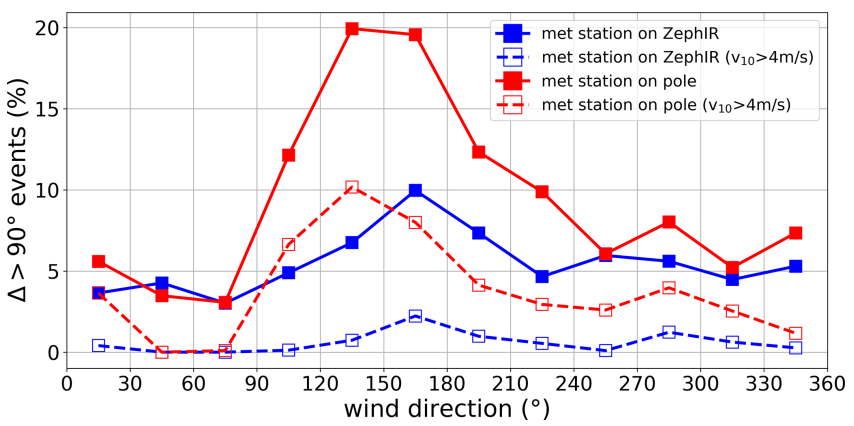

Figure 16. The $\Delta>90^{\circ}$ occurrence for the lowest measuring height of $11 \mathrm{~m}$ for different wind sectors (bin size $30^{\circ}$ ), separating the data regarding the location of the meteorological station and including a wind speed threshold of $4 \mathrm{~m} \mathrm{~s}^{-1}$ (as measured at $10 \mathrm{~m}$ ).

taken. The success of this correction scheme depends on the size of the natural wind veer between mast height and (highest) wind lidar measuring level, which should be well below $90^{\circ}$.

\section{Conclusions}

We have conducted a 2-year measurement campaign of the ZephIR 300 vertical profiling CW focusing wind lidar at the Cabauw site. We have studied the (height-dependent) data availability of the wind lidar under various meteorological conditions and the data quality of $10 \mathrm{~min}$ averaged horizontal wind speed and wind direction via a comparison with in situ wind measurements at several levels in the $213 \mathrm{~m}$ tall meteorological mast.

We find an overall availability of QC data of $97 \%$ to $98 \%$, where the missing part is mainly due to precipitation events exceeding $1 \mathrm{~mm} \mathrm{~h}^{-1}$ or fog or low clouds below $100 \mathrm{~m}$. Precipitation affects mostly the lower measuring levels; fog and low clouds affect the upper ones. The mean bias in the horizontal wind speed is within $0.1 \mathrm{~m} \mathrm{~s}^{-1}$ with a high correlation 
between the mast and wind lidar measurements, although under some specific conditions (very high wind speed, fog or low clouds) larger deviations are observed. The mean bias in the wind direction is within $2^{\circ}$, which is of the same order as the combined uncertainty in the alignment of the wind lidars and the wind vanes.

The $180^{\circ}$ error in the wind direction output occurs about $9 \%$ of the time, which is reduced when omitting low wind speeds. This percentage depends strongly on the amount of possible wind flow disturbance near the attached meteorological station. A correction scheme based on data of an auxiliary wind vane at a height of $10 \mathrm{~m}$ is applied, leading to a reduction of the $180^{\circ}$ error below $2 \%$ (or even well below $1 \%$ when considering wind speeds above $4 \mathrm{~m} \mathrm{~s}^{-1}$ ). This scheme can be applied in real-time applications in the situation that a nearby freely exposed mast with wind direction measurements at a single height is available.

In this work, we have focused on the most commonly used output for meteorology and wind energy purposes: $10 \mathrm{~min}$ averaged horizontal wind speed and wind direction. However, the wind lidar output also contains minimum, maximum and standard deviation of the horizontal wind speed and turbulence intensity, which are likely to be more sensitive to fundamental differences between the cup anemometer and the wind lidar (see, e.g. Sathe et al., 2011; Suomi et al., 2017), and therefore an intercomparison is recommended for those parameters as well. The vertical wind speed output might be compared with the sonic anemometers that are present at the 60,100 and $180 \mathrm{~m}$ mast levels. 


\section{Appendix A: Wind sector selection}

For the wind speed and wind direction intercomparison, the long free-flow wind sector between 200 and $250^{\circ}$ is selected. Here, we show some results on the wind speed intercomparison for the full range of wind directions. In Fig. A1, the relative deviation between the wind lidar and the mast wind speed measurements is shown as function of the wind direction (at $10 \mathrm{~m})$, in which the data are collected in bins of $20^{\circ}$, for wind speeds ranging between 4 and $16 \mathrm{~m} \mathrm{~s}^{-1}$. For the upper four heights, no wind direction dependence is observed, whereas for the lower two heights a clear modulation of the relative deviation is visible, with a negative deviation between 100 and $150^{\circ}$ and positive deviation between 250 and $300^{\circ}$. We explain this behaviour by the presence of flow obstruction at the remote sensing site and neighbouring trees SE of the wind lidars (for $100-150^{\circ}$ ), and neighbouring trees $\mathrm{NW}$ of the $\mathrm{C}$ masts (for $250-300^{\circ}$ ), in combination with the relatively large distance between the wind lidar and the reference masts. This last feature is absent in the present $11 \mathrm{~m}$ mast data, because the $\mathrm{D}$ mast is taken instead of the $\mathrm{C}$ mast.
In Fig. A2, a comparison between the linear regression results and the biases for different wind sectors is made, based on the present reference mast wind data set, and again for wind speeds ranging between 4 and $16 \mathrm{~m} \mathrm{~s}^{-1}$. The results for the slope (panel a) and the mean bias (panel c) clearly show sensitivity to the wind direction for the lower levels (up to $39 \mathrm{~m}$ ), whereas for the upper levels (from $80 \mathrm{~m}$ onwards) the results of the different wind sectors overlap. For the full profile, the $200-250^{\circ}$ wind sector provides the best results. The results for $R^{2}$ (panel b) and the standard deviation (panel d) show some variation among the different wind sectors over the full profile. For $R^{2}$, we note that the span is very narrow (well within 0.005) for the upper levels. For the standard deviation, the differences might be linked to the distinct wind speed distributions of the different wind sectors (see Fig. 2). For instance, the mean wind speed (within the 4-16 $\mathrm{m} \mathrm{s}^{-1}$ class) is the highest for the 150-200 and 200 $250^{\circ}$ wind sectors $\left(9.8 \mathrm{~m} \mathrm{~s}^{-1}\right.$ at $\left.200 \mathrm{~m}\right)$ and the lowest for the $300-360^{\circ}$ wind sector $\left(7.8 \mathrm{~m} \mathrm{~s}^{-1}\right.$ at $\left.200 \mathrm{~m}\right)$. 

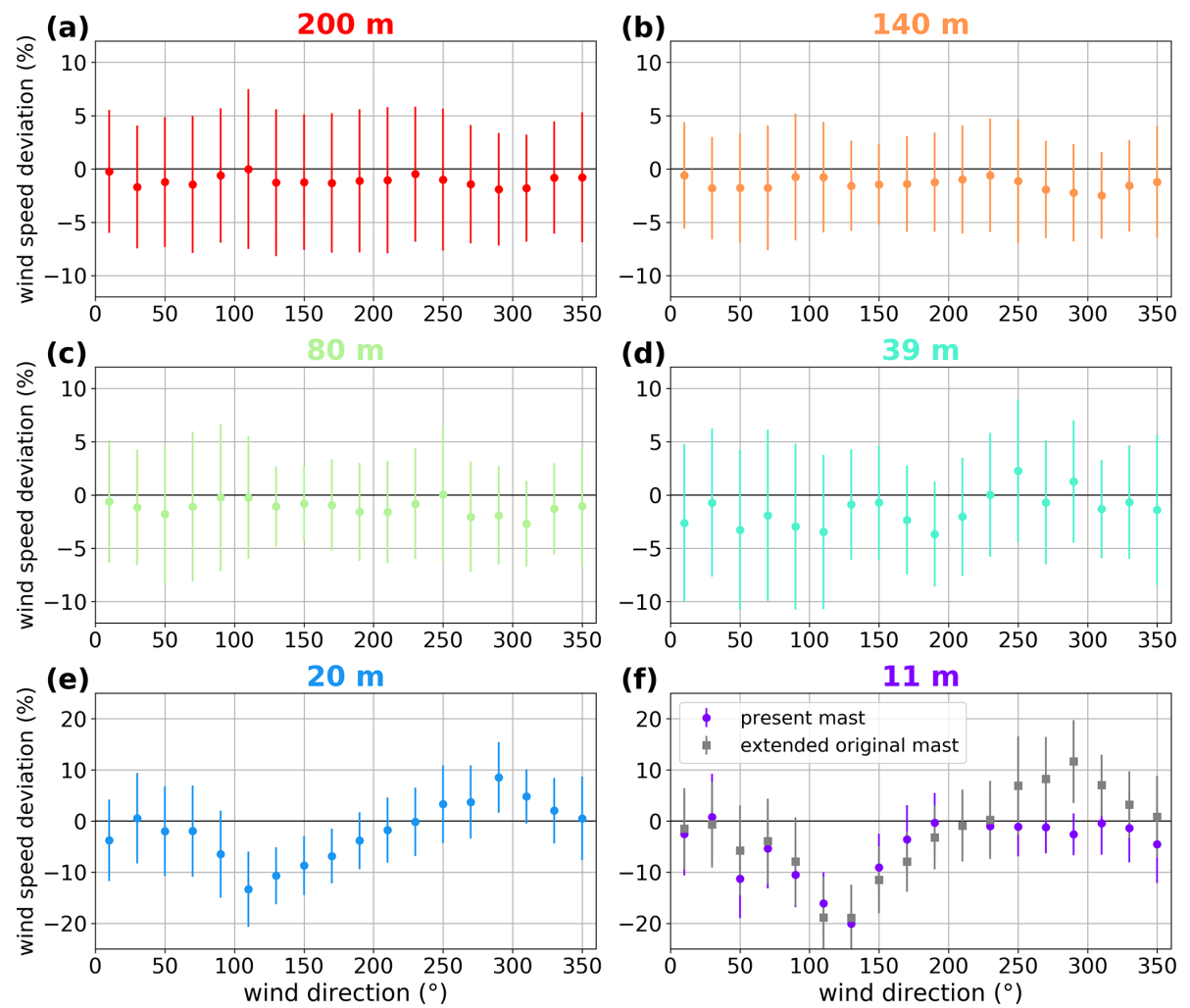

Figure A1. Relative deviation between the wind lidar and the mast wind speed measurements as function of wind direction (at $10 \mathrm{~m}$ ) for the different heights: (a) $200 \mathrm{~m}$, (b) $140 \mathrm{~m}$, (c) $80 \mathrm{~m}$, (d) $39 \mathrm{~m}$, (e) $20 \mathrm{~m}$ and (f) $11 \mathrm{~m}$. The data points represent the bin average and standard deviation (wind direction bin size is $20^{\circ}$ ). Wind speeds are bounded to the $4-16 \mathrm{~m} \mathrm{~s}^{-1}$ range. Note the different scales.

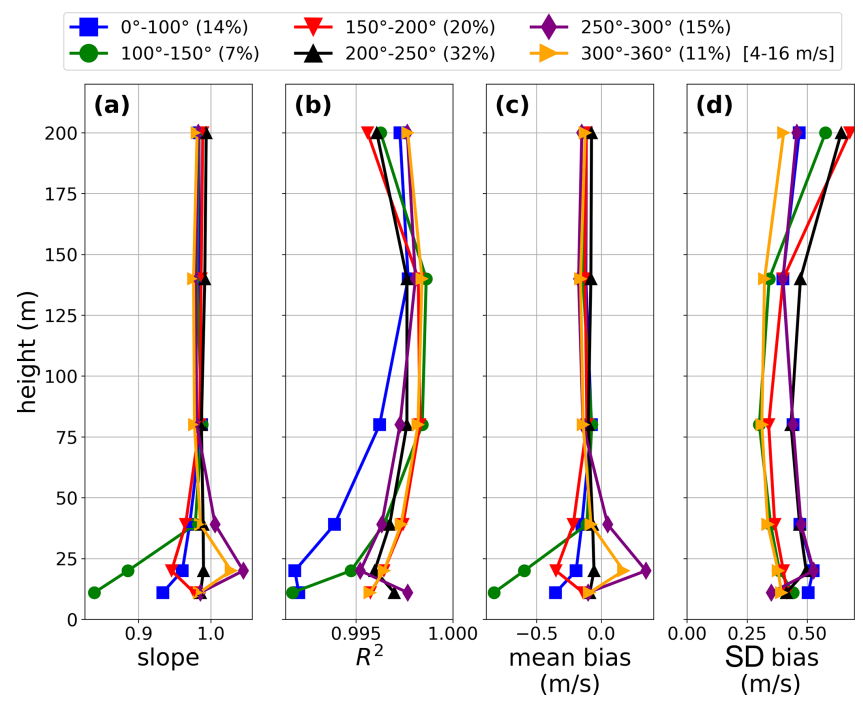

Figure A2. Profiles of linear regression analysis results and biases in the wind speed, applied to different wind sectors, where the wind speed is bounded to the $4-16 \mathrm{~m} \mathrm{~s}^{-1}$ range. Panels (a, b) show the parameters for a linear regression without offset, and panels $(\mathbf{c}, \mathbf{d})$ show the mean bias and standard deviation of the bias. The percentages in the legend indicate the occurrences of the different wind sectors. 
Code and data availability. Data sets and software codes are available at https://doi.org/10.5281/zenodo.3966868 (Knoop, 2020). Note that Cabauw tower and surface meteorological data are also available via https://dataplatform.knmi.nl/ (last access: 9 March 2021, KNMI, 2021).

Author contributions. SK was responsible for the wind lidar measurements, performed the data analysis and wrote the original draft. FB was responsible for the mast wind measurements and postprocessing. All co-authors contributed to refining the manuscript text.

Competing interests. The authors declare that they have no conflict of interest.

Special issue statement. This article is part of the special issue "Tropospheric profiling (ISTP11) (AMT/ACP inter-journal SI)". It is not associated with a conference.

Acknowledgements. We acknowledge Rijkswaterstaat Maritiem Informatievoorziening Service Punt (RWS-MIVSP) for supporting this measurement campaign and providing a ZephIR 300M instrument. We also acknowledge Alfons Driever (KNMI) for technical support.

Review statement. This paper was edited by Paolo Di Girolamo and reviewed by two anonymous referees.

\section{References}

Baas, P., Bosveld, F. C., Klein Baltink, H., and Holtslag, A. A. M.: A Climatology of Nocturnal Low-Level Jets at Cabauw, J. Appl. Meteorol. Clim., 48, 1627-1642, https://doi.org/10.1175/2009JAMC1965.1, 2009.

Bosveld, F. C.: The Cabauw In-situ Observational Program 2000 - Present: Instruments, Calibrations and Set-up, KNMI, Technical Report, TR-384, available at: http://bibliotheek.knmi.nl/ knmipubTR/TR384.pdf (last access: 13 January 2021), 2020.

Bosveld, F. C., Baas, P., Beljaars, A. C. M., Holtslag, A. A. M., VilàGuerau de Arellano, J., and van de Wiel, B. J. H.: Fifty Years of Atmospheric Boundary-Layer Research at Cabauw Serving Weather, Air Quality and Climate, Bound.-Lay. Meteorol., 177, 583-612, https://doi.org/10.1007/s10546-020-00541-w, 2020.

Courtney, M. S., Wagner, R., and Lindelöw, P.: Testing and comparison of lidars for profile and turbulence measurements in wind energy, IOP Conf. Series: Earth and Environmental Science, 1, 012021, https://doi.org/10.1088/1755-1307/1/1/012021, 2008.

Henderson, S. W., Gatt, P., Rees, D., and Huffaker, R. M.: Wind Lidar, Chap. 7, in: Laser remote sensing, edited by: Fujii, T. and Fukuchi, T., Taylor and Francis, Boca Raton, FL, USA, 469-722, 2005.
Kindler, D., Oldroyd, A., MacAskill, A., and Finch, D.: An eight month test campaign of the Qinetiq ZephIR system: Preliminary results, Meteorol. Z., 16, 479-489, https://doi.org/10.1127/09412948/2007/0226, 2007.

KNMI: KNMI Data Platform, KNMI, the Netherlands, available at: https://dataplatform.knmi.nl/, last access: 9 March 2021.

Knoop, S.: A two-year intercomparison of CW focusing wind lidar and tall mast wind measurements at Cabauw, Version v1, Data set, Zenodo, https://doi.org/10.5281/zenodo.3966868, 2020.

Kristensen, L.: The Cup Anemometer and Other Exciting Instruments, PhD thesis, Ris $\emptyset$ National Laboratory, Roskilde, Denmark, Ris $\varnothing-\mathrm{R}-615(\mathrm{EN}), 1993$.

Mikkelsen, T.: Remote sensing of wind, Chap. 1, in: Remote Sensing for Wind Energy, edited by: Peña, A., DTU Wind Energy-E-Report-0084(EN), available at: https://orbit.dtu.dk/ en/publications/remote-sensing-for-wind-energy-4 (last access: 13 January 2021), 2015.

Peña, A., Hasager, C. B., Gryning, S.-E., Courtney, M. S., Antoniou, I., and Mikkelsen, T.: Offshore Wind Profiling Using Light Detection and Ranging Measurements, Wind Energy, 12, 105124, https://doi.org/10.1002/we.283, 2009.

Pitter, M., Slinger, C., and Harris, M.: Introduction to continuouswave Doppler lidar, Chap. 5, in: Remote Sensing for Wind Energy, edited by: Peña, A., DTU Wind Energy-E-Report0084(EN), available at: https://orbit.dtu.dk/en/publications/ remote-sensing-for-wind-energy-4 (last access: 13 January 2021), 2015.

Sathe, A., Gottschall, J., Mann, J., and Courtney, M.: Can Wind Lidars Measure Turbulence?, J. Atmos. Ocean. Tech., 28, 853868, https://doi.org/10.1175/JTECH-D-10-05004.1, 2011.

Smith, D. A., Harris, M., Coffey, A. S., Mikkelsen, T., Jørgensen, H. E., Mann, J., and Danielian, R.: Wind lidar evaluation at the Danish wind test site in Høvsøre, Wind Energy, 9, 87-93, https://doi.org/10.1002/we.193, 2006.

Stoffelen, A., Pailleux, J., Källén, E., Vaughan, J. M., Isaksen, L., Flamant, P., Wergen, W., Andersson, E., Schyberg, H., Culoma, A., Meynart, R., Endemann, M., and Ingmann, P.: The atmospheric dynamics mission for global wind field measurement, B. Amer. Meteor. Soc., 86, 73-87, https://doi.org/10.1175/BAMS-86-1-73, 2005.

Suomi, I., Gryning, S.-E., O'Connor, E. J., and Vihma, T.: Methodology for obtaining wind gusts using Doppler lidar, Q. J. Roy. Meteor. Soc., 143, 2061-2072, https://doi.org/10.1002/qj.3059, 2017.

van Ulden, A. P. and Wieringa, J.: Atmospheric boundary layer research at Cabauw, Bound.-Lay. Meteorol., 78, 39-69, 1996.

Verkaik, J. W. and Holtslag, A. A. M.: Wind profiles, momentum fluxes and roughness lengths at Cabauw revisited, Bound.Lay. Meteorol., 122, 701-719, https://doi.org/10.1007/s10546006-9121-1, 2007.

Wauben, W.: Wind Tunnel and Field Test of Three 2D Sonic Anemometers, KNMI, Technical Report, TR-296, available at: http://bibliotheek.knmi.nl/knmipubTR/TR296.pdf (last access: 13 January 2021), 2007.

Wouters, D. A. J. and Wagenaar, J. W.: Verification of the ZephIR 300 LiDAR at the ECN LiDAR Calibration Facility for the offshore Europlatform measurement campaign, ECN-M-16-029, available at: https://publications.ecn.nl/ECN-E-16-029 (last access: 13 January 2021), 2016. 